\title{
Effect of Sea Water Temperature on Egg Size of Japanese Anchovy*1
}

\author{
Chifumi Imai*2 and Syoiti Tanaka*3 \\ (Accepted August 4, 1987)
}

\begin{abstract}
Egg size change of Japanese anchovy dependent upon sea water temperature is described. Length of chorion was selected as the representative egg size character based on comparisons with some other characters, and referred to as egg diameter. Egg diameter changed seasonally and geographically. Mean egg diameter of net samples had significant negative correlation with surface water temperature. This correlation seemed to be universal regardless of time and locality.

Spawning experiments confirmed the effect of temperature on egg size. Yearly variation of egg size spawned in an aquarium corresponded to trend of temperature anomalies of each year. Egg size could be experimentally enlarged by cooling rearing water.

Stability of the anchovy population was discussed in connection with reproductive strategy. Egg size change through temperature information seemed to be beneficial to reproduction from the viewpoint of abundance of food and predator and size of food organisms. The strategy regarded as the key to stability was that reproductive energy was invested dispersally to long spawning season. This strategy was based on the ability to accumulate reproductive energy quickly and on the eurythermal nature of the species.
\end{abstract}

Survival of pelagic larvae is one of major problems in the population ecology of marine fishes. Especially, researches on the effects of both biotic and abiotic environments on survival of larvae would become keys to elucidate mechanisms of population fluctuation of marine teleosts.

In general, it has been considered that the transition period from yolk-sac to external nutrition is most critical. ${ }^{1,2)}$ Lasker et al. ${ }^{3)}$ mentioned that point of no return (PNR) of northern anchovy Engraulis mordax was 2 days after completion of yolk absorption, while grunion ${ }^{4)}$ or sand eel ${ }^{53}$ had essentially no apparent PNR. This difference would probably be caused by differences in quantity and quality of yolk and special ecology of early larvae of each species. This suggests that larvae of different species have different possibilities of survival even in the same environment, depending upon their own survival potential. Similar phenomenon of intra-specific one could also be expected. If larvae have more yolk nutrient, they will have longer periods to PNR and a greater chance to search suitable food patches. If the quality and quantity of yolk nutrient are changed by any environmental factor, the survival rate of early larvae and recruitment success thereafter of one species will be influenced by the factor.

Blaxter and Hempel ${ }^{(6)}$ reported difference of biological features, including PNR, among Atlantic herring stocks. This difference might be dependent on egg size. Thus egg size is an important factor varying survival potential of first-feeding larvae, because it will be related with body and mouth sizes of larvae, ${ }^{6,7)}$ swimming speed $^{82}$ and so on. The ultimate objective of our studies is to examine the effects of environmental factors on early survival of pelagic larvae. In order to approach this problem, we will report in this paper on temperature controlled change of egg size of Japanese anchovy Engraulis japonica based on temporal and spatial comparison of egg size and on spawning experiments.

The Japanese anchovy population has been stable in abundance compared with other pelagic species such as sardine or saury. This seems virtually impossible considering its small size and short longevity. This point will be discussed based on reproductive strategy.

\section{Materials and Methods}

\section{Measurement of egg size}

Eggs of anchovy are ellipsoidal in shape, with

*1 Part of this research was aided by financial aids for scientific research.

*2 Department of Fisheries, Shimonoseki University of Fisheries, Shimonoseki 759-65, Japan (今非千文: 水産大学校漁業学科).

*3 Department of Fisheries Resouces Management, Tokyo University of Fisheries, Minato, Tokyo 108, Japan (田中昌一: 東京水应大学资源管理学科). 
no oil globule and narrow perivittelin spaces. Length and width of chorions and yolks were measured using the following method.

Each sample consisted of more than 100 eggs was magnified and photographed using a profile projector with a pre-measured gauge $(2-3 \mathrm{~mm}$ in length). Both ends of these photo-imaged eggs and the gauge were plotted on a flat of digitizer. The program DIG* accepts their X-Y coordinates and calculates length of eggs based on gauge length input. Individual length data were recorded on a floppy disk. This procedure could save much time when measuring the size of thousands eggs. Supplementally, egg dimensions were measured by ocular micrometer of binocular microscope to nearest $0.025 \mathrm{~mm}$. Volume of chorions and yolks were estimated as $\pi / 6 \times$ length $x$ width $^{2}$.

More than 100 eggs from each sample were divided into three parts, and after counting number of eggs in each part, they were dried at $70^{\circ} \mathrm{C}$ for more than 24 hours and weighed to the nearest $1 \mu \mathrm{g}$. The mean value of average weight of one egg from three parts was used as mean dry weight of one sample and was calculated by $\mathrm{mg}$ value per 100 eggs.

Measurements of both length and weight were made after more than a month from fixation, because it is reported that shrinkage of egg size and weight loss by dehydration was finished within this period..$^{8,10)}$

\section{Egg Samples}

Both eggs of net samples and those spawned in aquaria were used. Egg samples were fixed and preserved in sea water of $5-10 \%$ formalin, except for aquarium samples, which were measured live for the purpose of comparison.

Two series of monthly samples from Sagami Bay surveys carried out by Kanagawa Prefectural Fisheries Experimental Station were used. One was consisted by surface tows of Maruchi-A type larva net June, 1977 through March, 1978 at 9 stations located in the eastern half of Sagami Bay. Another was operated by simultaneous horizontal tows of MTD nets April through September 1980 at 4 stations west of Joga-shima. ${ }^{11}$ In Otsuchi Bay surveys, anchovy eggs were collected only in June, 1978 by surface tows of MTD nets. Samples of Ise Bay areas were collected by vertical tows of MTB nets in the routine works on fishery and oceanography by Aichi and Mie Prefectural Fisheries Experimental Stations.

\section{Spawning Experiments}

Spawning experiments were carried out at Misaki Marine Biological Station, University of Tokyo (MMBS) in 1980, 1982 and 1984. Adult anchovy fished and reared in pens at sea at Kaneda or Koajiro for live bait for the skipjack hook and line fishery were used. At mid-May or earlyJune of each year, adults were transported to MMBS in two 500 litre tanks with oxygen supplied. If handling could be completed within 1 hour, 300-5000 adults could be transferred without significant loss. A $12 \mathrm{t}$ outdoor aquarium of $0.7 \mathrm{~m}$ depth was used. About $80 \%$ of surface was covered with bluecolor polyvinyl sheet for shading direct sunlight and for tranquilizing the fish. About 50 liters of fresh sea water with no filtration system was supplied and over-flowed every minute. Compound diet for trout juveniles (crumble 2c) or fresh water misids were used as food. Within two days after transfer, almost all specimen began feeding. If condition of fish was good, spawning was commenced within one week with no artificial technique. Spawning occurred at night, mainly during 20-22 o'clock, similar to field observations. ${ }^{11,12)}$ Strong lighting during night inhibited spawning. Through early October, spawning was observed almost every night. Floating eggs were collected by the trap consisted by net and bottle, devised at overflow.

Spawning experiments with temperature control were carried out in $4 \mathrm{t}$ volume indoor aquarium. Water system was the same as for the outdoor aquarium, but less water was used to maintain efficiency of the cooling unit. A circular type water cooler was used.

\section{Results}

\section{Egg Size Measurement}

Since all length distributions of eggs from one night spawning were monomodal, we use the term batch to an egg group collected during one night regardless of number of females spawned in an aquarium. In order to know ontogenetic change of egg size, one batch was developed at $20^{\circ} \mathrm{C}$ and 50 eggs were measured once every 5 hours live and fixed. Mean and standard deviation of dimensions of chorions and yolks and dry weights per 100 eggs are shown in Table 1. Dimensions of chorions were nearly constant throughout development, while those of yolks decreased with development of embryos. Chorion size decreased

* BASIC program structured by C. Imai for Apple II microcomputer with HI-PAD digitizer. 
Table 1. Egg size characters of Oct. 1st, 1984 batch developed at $20^{\circ} \mathrm{C}$ measured 5 hour interval. Each value indicates mean and standard deviation in parenthesis

\begin{tabular}{|c|c|c|c|c|c|c|c|c|}
\hline & \multirow[b]{2}{*}{2.5} & \multicolumn{7}{|c|}{ Time after fertilization (hour) } \\
\hline & & 7.5 & 12.5 & 17.5 & 22.5 & 27.5 & 32.5 & 36.5 \\
\hline \multicolumn{9}{|c|}{ Chorion length $(\mathrm{mm})$} \\
\hline (live) & $1.195(.063)$ & $1.193(.066)$ & $1.180(.045)$ & $1.188(.056)$ & $1.191(.054)$ & $1.191(.072)$ & $1.179(.053)$ & $1.168(.053)$ \\
\hline (fixed) & $1.187(.064)$ & $1.182(.069)$ & $1.175(.064)$ & $1.166(.063)$ & $1.172(.055)$ & $1.190(.061)$ & $1.200(.069)$ & $1.167(.068)$ \\
\hline fixed/live $(\%)$ & 99.3 & 99.1 & 99.6 & 98.1 & 98.4 & 99.9 & 101.8 & 99.9 \\
\hline \multicolumn{9}{|l|}{ Yolk length (mm) } \\
\hline (live) & $1.195(.063)$ & $1.095(.052)$ & $1.091(.037)$ & $.988(.051)$ & $.960(.051)$ & $.927(.059)$ & $.908(.060)$ & $.903(.058)$ \\
\hline (fixed) & $.892(.069)$ & $.867(.074)$ & $.869(.079)$ & $.821(.048)$ & $.774(.042)$ & $.815(.046)$ & $.857(.057)$ & $.861(.052)$ \\
\hline fixed/live $(\%)$ & 74.6 & 79.2 & 79.7 & 83.1 & 80.6 & 87.9 & 94.4 & 95.3 \\
\hline \multicolumn{9}{|l|}{$\begin{array}{l}\text { tixed/live }(\%) \\
\text { Chorion width (mm) }\end{array}$} \\
\hline (live) & $.623(.025)$ & $.621(.025)$ & $.612(.023)$ & $.602(.027)$ & $.613(.023)$ & $.614(.024)$ & $.606(.025)$ & $.615(.021)$ \\
\hline (fixed) & $.599(.028)$ & $.591(.029)$ & $.590(.042)$ & $.589(.026)$ & $.597(.033)$ & $.606(.025)$ & $.612(.027)$ & $.598(.025)$ \\
\hline fixed/live $(\%)$ & 96.1 & 95.2 & 96.4 & 97.8 & 97.4 & 98.7 & 101.0 & 97.2 \\
\hline \multicolumn{9}{|l|}{$\begin{array}{l}\text { fixed/live }(\%) \\
\text { Yolk width (mm) }\end{array}$} \\
\hline (live) & $.623(.025)$ & $.621(.025)$ & $.612(.023)$ & $.602(.027)$ & $.613(.023)$ & $.614(.024)$ & $.601(.027)$ & $.613(.021)$ \\
\hline (fixed) & $.562(.045)$ & $.503(.033)$ & $.483(.027)$ & $.489(.038)$ & $.493(.033)$ & $.488(.038)$ & $.503(.035)$ & $.492(.031)$ \\
\hline fixed/live (\%) & 90.2 & 81.0 & 78.9 & 81.2 & 80.4 & 74.5 & 83.7 & 80.3 \\
\hline \multicolumn{9}{|l|}{$\begin{array}{l}\text { nxed/nve }(\%) \\
\text { Dry weight }\end{array}$} \\
\hline per 100 eggs (mg) & 1.825 & 1.783 & 1.770 & 1.778 & 1.759 & 1.788 & 1.797 & 1.647 \\
\hline
\end{tabular}


a little through fixation, but yolks shrank considerably. Since initial size of chorion and yolk was nearly equal and chorion is stable, chorion size is a more appropriate estimator of initial amount of yolk.

The relationships between various size characters
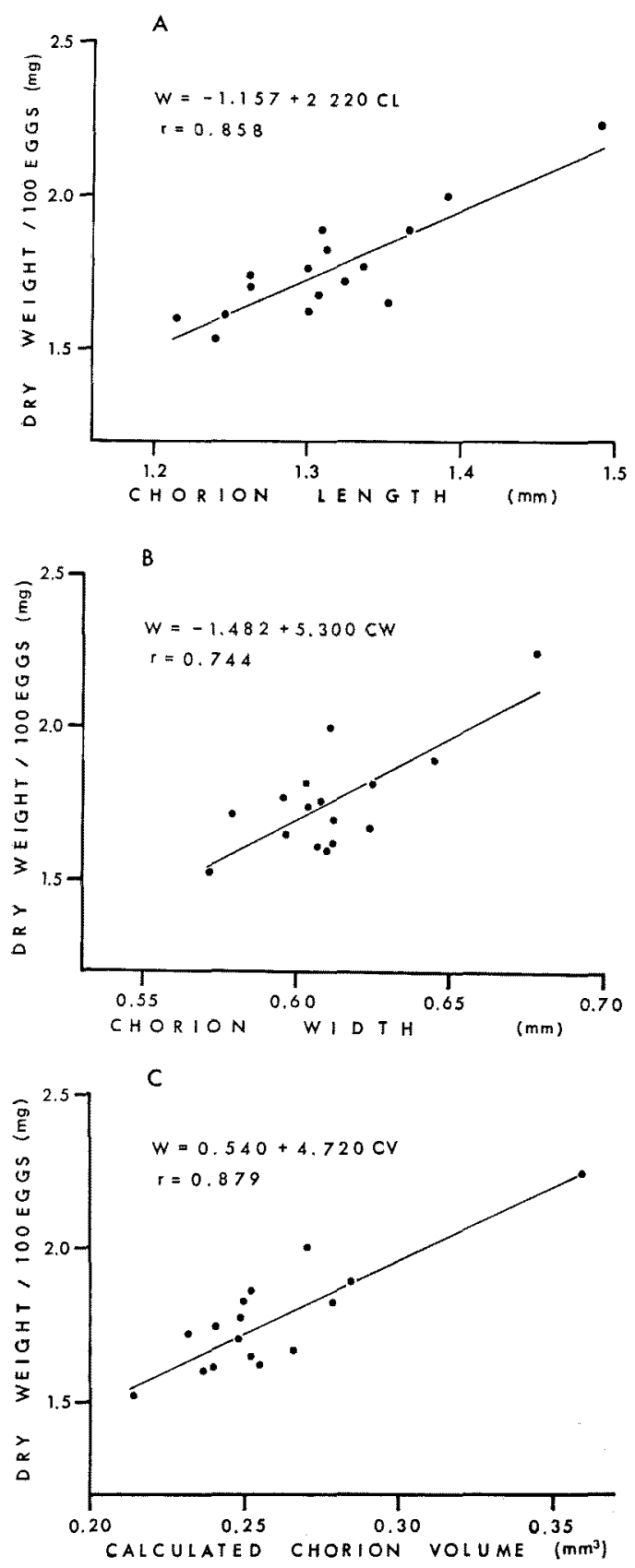

Fig. 1. Relationships between mean chorion length (A), width (B) and calculated volume (C) and dry weight for 16 batches spawned in 1984 . of 16 aquarium batches in 1984 spawning season are shown in Fig. 1. Mean length (A), width (B) and calculated volume (C) of chorions were all positively correlated with dry weight $(p<0.01)$. Correlation coefficients were $0.858,0.744$ and 0.879 , respectively. Because the ratios of mean width/mean length varied within a range of $0.438-$ 0.502 , it is easily expected that correlation coefficient between calculated volume and dry weight is highest. Improvement of coefficient of determination $\left(r^{2}\right)$, however, was only $3 \%$ by using the calculated volume instead of length. It was considered that dry weight of eggs was sufficiently indicated by mean chorion length. We decided to adopt chorion length to express egg size and to refer it as egg diameter.

Seasonal and Geographical Changes in the Egg Size of Net Samples

All net samples consisted of eggs of two or three developmental stages. Each stage of eggs was considered to correspond to separate spawning dates. Mean diameter was calculated on 100 eggs randomly selected or all eggs (if the number of eggs was less than 100) from each stage of each sample. Two way analysis of variance indicated significant $(p<0.01)$ monthly difference of mean egg diameter, but no significant difference was observed among collecting depth and stations and among developmental stages. Since mean diameter does neither differ by stations nor by developmental stages, mean egg diameters of each month was expressed by pooled mean. All frequency distributions of egg diameter were monomodal normal type (Fig. 2).

Monthly means and standard deviations of egg diameter and mean surface temperature at Sagami and Otsuchi Bays are shown in Fig. 3. Marked seasonal changes of egg diameter are considered to be connected with surface temperature. Eggs were large in cold winter-spring months and size decreased with increasing temperature toward summer. Egg size again increased corresponding to cooling of the sea. This cycle seems to be repeated every year. A maximum of $1.46 \mathrm{~mm}$ was recorded in March 1978 with surface temperature of $15.7^{\circ} \mathrm{C}$ and the minimum was $1.18 \mathrm{~mm}$ in August $1980\left(24.4^{\circ} \mathrm{C}\right)$. In Otsuchi Bay where spawning was restricted to summer months, sufficient eggs of anchovy were collected only during June 1978. These eggs had a mean diameter of $1.43 \mathrm{~mm}$ which is significantly larger ( $p<0.01$, student's $t$-test) than that for the same season in Sagami Bay. A similar trend was 

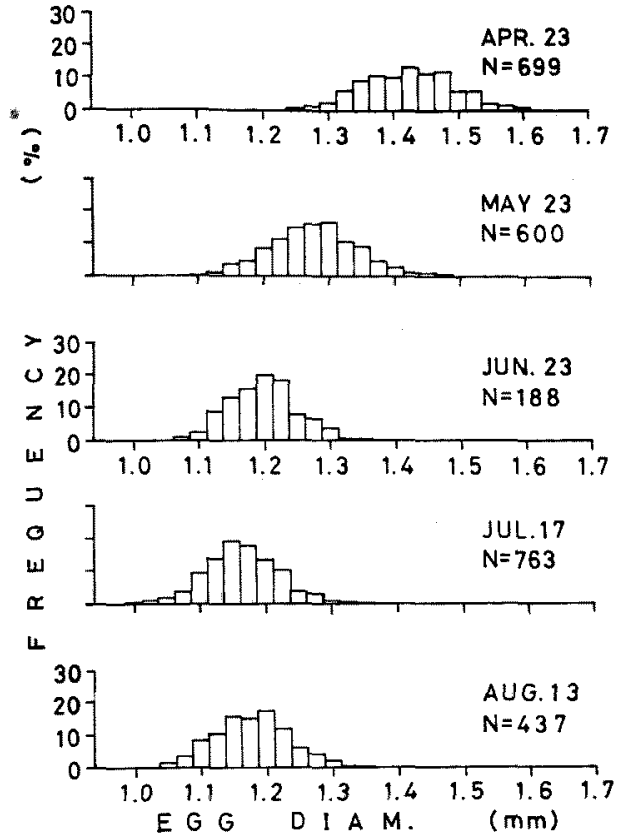

Fig. 2. Frequency distributions of egg diameter from Sagami Bay, 1980 surveys.



Fig. 3. Seasonal changes of mean egg diameter and mean surface temperature in Sagami and Otsuchi Bays, 1977-1980. Vertical bars indicate standdard deviation of each sample.

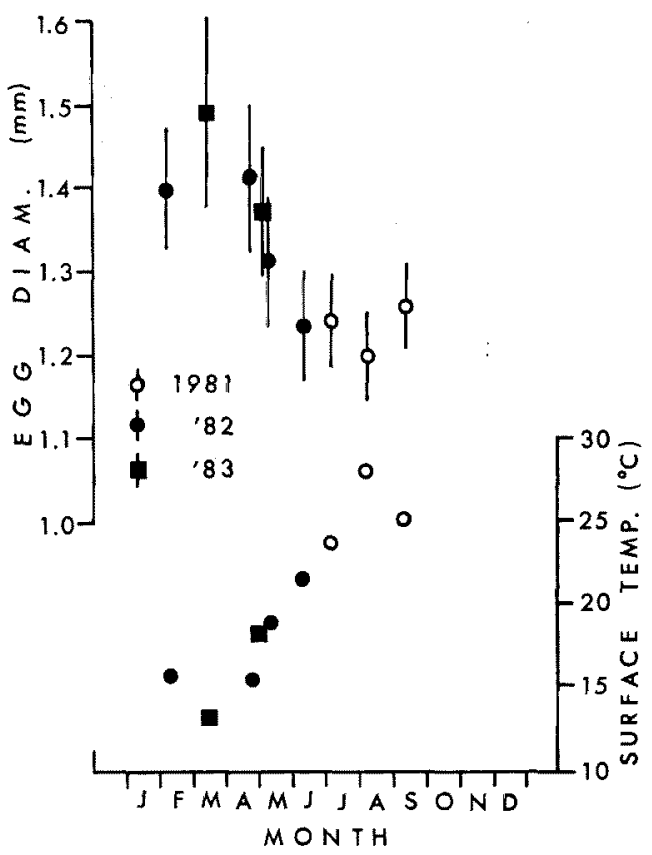

Fjg. 4. Seasonal changes of mean egg diameter and mean surface temperature in Ise Bay area, 19801983. Vertical bars indicate standard deviation of each sample.

recognized in egg size in Ise Bay area (Fig. 4), where the maximum of all data, $1.49 \mathrm{~mm}$ was recorded in March 1983 under $13.2^{\circ} \mathrm{C}$. Fig. 5 shows correlation of mean egg diameter with sea water temperature for these data and also data from the Pacific coast of Kyushu reported by Asami. ${ }^{13)}$ A highly significant negative correlation $(r=-0.856, p<0.01)$ was observed. It seems that an egg size-temperature correlation exists universally regardless of time and area. Negative correlation is more marked in the lower range temperature and becomes vague over about $20^{\circ} \mathrm{C}$.

\section{Spawning Experiments}

Seasonal changes of mean and standard deviation of egg diameter spawned in outdoor aquarium in 1980,1982 , and 1984 with water temperatures are shown in Fig. 6. Decreasing trends of egg size from May through July were not marked in 1980 and 1982. In these two years water temperature had already been over $20^{\circ} \mathrm{C}$ in late May when rearing experiments started. On the other hand, eggs spawned in May and June of 1984 were significantly larger than the previous two cases. Egg size decreased remarkably with increasing 


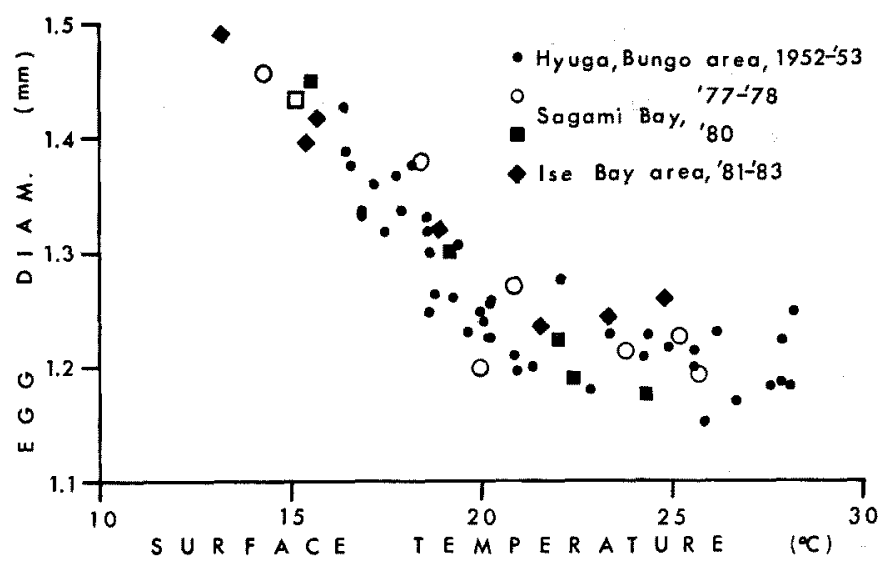

Fig. 5. Correlation of egg diameter with surface water temperature.
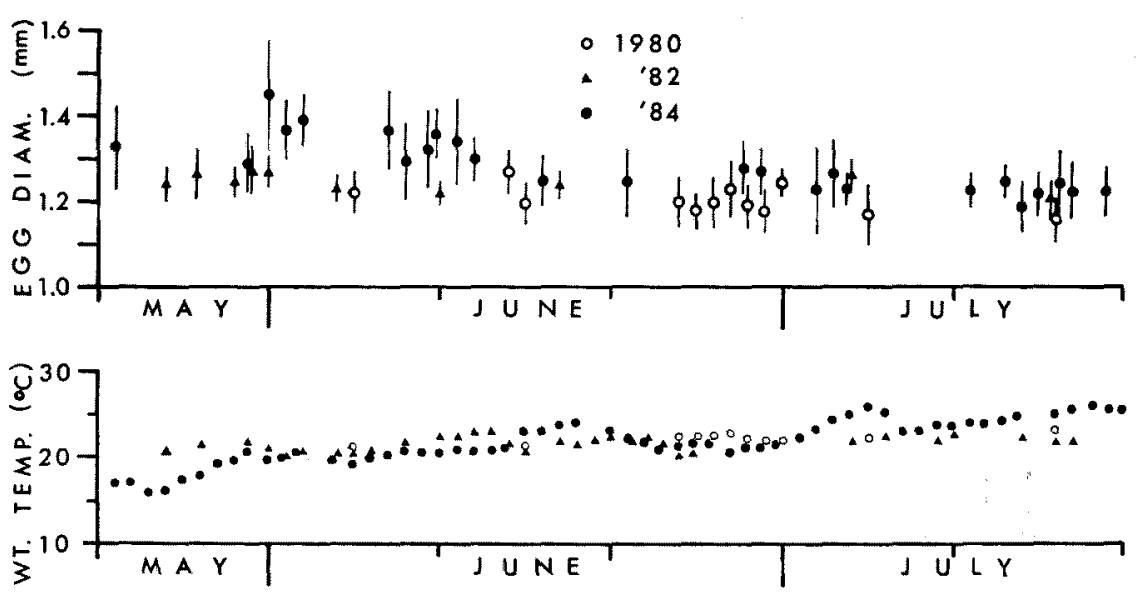

Fig. 6. Changes of mean diameter of eggs spawned in an aquarium and water temperature for 1980,1982 and 1984 . Vertical bars indicate standard deviation of each sample.

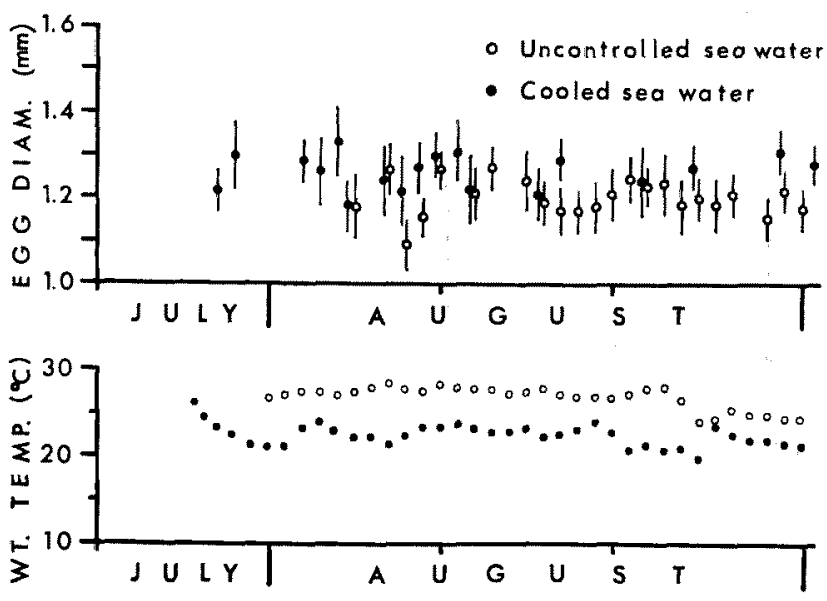

Fig. 7. Comparison of mean diameter of eggs spawned in cooled and normal temperature aquaria. Vertical bars indicate standard deviation of each sample. 
water temperature. Water temperature was about $16^{\circ} \mathrm{C}$ even in mid-May and well below normal years in June and July in 1984. This suggests that egg size differs year to year connected with sea water temperature especially with timing and magnitude of spring warming.

The results of spawning experiments with temperature controlled aquarium carried out in August 1984 are shown in Fig. 7. Egg sizes of cooled aquarium were larger than that of uncontrolled one. Overall mean egg diameter of cooled aquarium $(1.264 \pm 0.043 \mathrm{~mm})$ was significantly larger ( $p<0.01$ by student's $t$ test) than that of normal one $(1.210 \pm 0.050 \mathrm{~mm})$. It was proved that to enlarge egg size of anchovy artificially is possible by cooling water temperature. We conclude that water temperature is a major factor controlling egg size of Japanese anchovy.

\section{Discussion}

First-feeding larvae of clupeoid species are especially vulnerable to starvation. Lasker et al..$^{33}$ reported that the point of no return (PNR) of first-feeding northern anchovy larvae was two days after yolk absorption. If an egg has more yolk energy, PNR will be increased and larva will have an enhanced ability to endure starvation. Blaxter and Hempel ${ }^{\mathrm{\theta}}$ noted that larger larvae from larger eggs of spring spawning Atlantic herring had a longer period of PNR than for smaller summer-autumn spawners. The amount of yolk energy should be an important factor for the early survival potential of first-feeding larvae. Egg size could be considered as an index of yolk energy available to early larvae.

Carloric content or dry weight may be better indices to express yolk energy than diameter or volume of eggs as the quality of yolk could vary. These methods, however, necessitates killing eggs and the egg samples are thus lost. Imai ${ }^{147}$ carried out rearing experiments, in which eggs were classified into length classes, and compared the survival potential of larvae in each class. Survival potential of hatched larvae of each length class was well reflected by the egg size differences. Since length measurement can be carried out even on live eggs, it has an advantage that survival of larvae hatched from measured eggs can be examined directly in such experiments. Furthermore, the anchovy egg is small in size and effect of weighing error may be relatively large. It is considered that the effects of treatment errors were rather small in length measurement.
Since yolk size decreases through development of embryo, size measurement has to be carried out at a specific stage. This might be impossible for net samples which contain eggs of various stages. On the other hand, chorion size did change little through development and fixation (Table 1). In early stages, the perivitteline space is narrow and sizes of chorion and yolk are almost equal. Chorion size at any stages of development can be a good index of initial size of yolk. Correlations between dry weight and chorion dimensions were all significant. Correlation coefficient was highest in calculated volume, but the difference was small between calculated volume and chorion length. The results of rearing experiments showed that survival ability of early larvae is correlated well with egg diameter..$^{143}$ Based on the above reasons, we employed chorion length as an index of egg size and referred as egg diameter.

The seasonal change of egg size of the Japanese anchovy corresponds quite well to seasonal changes of sea water temperature. A similar phenomenon was reported on cornish pilchard Sardina pilchardus. ${ }^{16)}$ In the northern part of Honshu (Otuchi Bay) where sea water temperature is low even in summer, eggs were large even in June. The annual trend of spring sea water temperature was well reflected on sizes of spawned eggs in an aquarium. Larger eggs were produced by cooling water even in summer. Asami ${ }^{13)}$ and Southward and Demiri ${ }^{15}$ ) suggested that water temperature might be the controlling factor of egg size based on field observations. This view is confirmed in the present study having shown the egg size-water temperature correlation which universally exists over a wide geographic and temporal scale and changed egg size successfully by controlling water temperature. We now conclude that sea water temperature is the main factor for controlling egg size of anchovy.

The effect of temperature was marked in the lower range of temperature. The effect weakened over about $20^{\circ} \mathrm{C}$, but results of rearing experiments showed that it would be weak but not zero. Precise examinations about the mechanism of temperature control were not carried out as temperature of aquaria could not be finely fixed.

A view that egg size change is related with size or age of spawning female has been argued in past papers. Bagenal ${ }^{16)}$ regarded the change of egg size of North Sea plaice as a progressive change with age of spawning female. Similar phenomena were reported on some salmonid 
species. ${ }^{17,18)}$ Although size or age of spawning female is one of the principal causes of change in egg size of these species, the results of this paper show that change in egg size of Japanese anchovy differs essentially from these species. Egg size changes correspond well with sea water temperature, and spawning experiments suggested that egg size of one female can be enlarged by lowering water temperature. Furthermore, various size and age of anchovy females spawn simultaneously and individual female spawns repeatedly. ${ }^{14,183}$ Thus, seasonal change of egg size of anchovy is not related with size or age of spawning females.

The theory of life history strategy proposes that fewer large eggs are adaptive to oligotrophic crrcumstances where abundance of food is critical, while numerous small eggs are advantageous to eutrophic circumstances where predation risk is more critical than food supply. $\left.{ }^{20}, 21\right)$ Although the concept is principally oriented in long term evolutronary sense, it can be extended to short term seasonal change of anchovy egg size. Cushing22? reviewed general form of production cycle of the sea, where in temperate areas production is low in winter and phytoplankton outburst occurs in spring and autumn. The phytoplankton outburst will be followed by production of hervivores and carnivores. Since the main food organisms of larval anchovy are small hervivorous zooplanktons represented by copepod nauplii, the best condition for survival of anchovy larvae will occur slightly after outburst of phytoplankton when predator organisms have not yet increased. Therefore it can be considered that the biotic environment of the sea in general form will succeed from oligotrophic to eutrophic with increasing temperature. Larger larvae of higher ability to endure starvation will be adaptive to the cold season when oligotrophic conditions are predicted. On the other hand, to increase the number of larvae will be important in warmer eutrophic seasons when predation risk will become more critical than lack of food.

It should also be noticed that egg size change is adaptive to size of food organisms. It is reported that mean size of copepod nauplii, which are considered as the most important food organism of pelagic fish larvae, decrease seasonally. ${ }^{23)}$ This is probably because larger cold water species reproduce at lower temperature and smaller tropical or temperate species do at higher temperature. ${ }^{24)}$ Larger larvae with larger mouth will be advantageous to larger food organisms.
The Japanese anchovy population has numerous seasonal cohorts as the spawning season is long, with the majorities occurring in spring and summer-autumn. Seasonal change of egg abundance, however, does not coincide with generation of these cohorts. In particular, egg generation was rather low in the spring cohort season. ${ }^{25}$ This fact suggests that the generation of these cohorts would be related with the good condition for survival of larvae mentioned above. Cushing 22) proposed the match/mismatch theory and it postulates that recruitment success is dependent on match or mismatch of spawning to the production cycle of the sea. These cohorts would be generated as a result of match to such good condition.

It has been known that population size of the spring cohort is larger than the summer-autumn cohort and that its fluctuation is a major factor in anchovy stock fluctuation. ${ }^{28,27)}$ Since the spring cohort may be originated from a smaller number of large eggs, it could be expected that the spring cohort has a higher survival potential. It has been confirmed by rearing experiments that larvae from larger eggs are larger at first-feeding feeding stage and have a higher ability of feeding. ${ }^{14}$ )

The key to recruitment success of the spring cohort may be whether sufficient numbers of eggs are spawned during the good conditions or not. In the last decade, the anchovy stock has decreased somewhat and poor spawning in early spring has been reported. ${ }^{25)}$ On the other hand, Japanese sardine, which favors cooler water and spawns earlier than anchovy, has been very abundant over the decade. Sardine would utilize the good condition of larval survival even in lower temperature, but anchovy would not because they favors warmer water than sardine.

On the other hand, the summer-autumn cohort is known to be rather small but less variable in abundance. This cohort is originated by smaller eggs of lower survival potential. It has already been argued that larger number of smaller eggs is adaptive to the summer-autumn season, when predation is more critical. Although egg survival is expected to be low, numerous eggs, will be effective to maintain a certain number of recruits. Since larger number of eggs are spawned over longer season, the effect of match/mismatch may be relaxed. Thus the fluctuation in number of summer-autumn eggs is considered to be less critical than for spring eggs and the cohort is therefore more stable. 
It has been known that stock abundance of anchovy is the most stable among pelagic species in the waters around Japan. Total landings have văried between' 130000 and $440000 \mathrm{t}$ per annum, while sardine landing fluctuated from 10000 to $4000000 \mathrm{t}$. This would appear contrary as anchovy has a shorter longevity and is smaller than the sardine. We speculate that the key to the stability of the anchovy population is the highly adaptive nature of this species. One adaptation is a long spawning season over a wide geographic area. This owes to its eurythermal nature and the ability for quick accumulation of reproductive energy. The fecundity of the anchovy is not so big due to its small body size, but the adult anchovy can spawn throughout almost all seasons and individual females spawn repeatedly in iniervals of a few days. ${ }^{14,18)}$ The second is the most important from the viewpoint of this paper. It is the specific ability that size and number of eggs can be elastically adjusted to environment through information of water temperature. This adaptation should efficiently increase the survival potential of larvae over variable conditions.

This strategy of high reproductive energy dispersed over wide and variable conditions will be advantageous to lowen risks and to maintain the average stock in a highly variable environment. As a result, the anchovy has a complex stock structure represented by spring and summerautumn cohorts. During severe conditions, various small cohorts, such as the summer-autumn cohort, will maintain the spawning stock, while the spring cohort will become prosperous and the whole stock will increase if conditions are improved. ${ }^{27)}$ The magnitude of match or mismatch in the total stock is always maintained within moderate levels. This strategy of variable stock structure with long and dispersed spawning is the key to the stability of the anchovy population. As one year's catastrophe will lead to extreme reduction of spawning stock in these short lived species, a strategy oriented towards stable recruitment seems to be essential to the conservation of this species.

\section{Acknowledgments}

We thank Isamu Mitani and Naohiro Nakata of Kanagawa Prefectural Fisheries Experimental Station for use of egg samples and convenience to obtain adult anchovy. Thanks are also expressed to Dr. Hideo Sekiguchi of Mie University, Shigeo
Funakoshi and Bunzo Hayashi give us chance to measure egg samples. We wish to thank Prof: Kinoshita and fellows of Misaki Marine Biological Station, University of Tokyo, for utilization of rearing facilities. We also thank Byron Sigel of the Ocean Research Institute for critical reading of the manuscript.

\section{References}

1) J. Hjort: Rapp. P.-v. Reun. Cons. Int. Explar. Mer, 20, 1-228 (1914).

2) R.C. May: in "The Early Life History of Fish" (ed. by J. H. S. Blaxter), Springer-Verlag, Berlin, 1974, pp. 1-29.

3) R. Lasker, H. M. Feder, G. H. Theilacker, and R. C. May: Mar. Biol., 5, 345-353 (1970).

4) R. C. May: Fish. Bull., 69, 411-425 (1971).

5) Y. Yamashita and T. Aoyama: Nippon Suisan Gakkaishi, 52, 635-639 (1986).

6) J. H. S. Blaxter and G. Hempel: J. Cons., 28, 211-240 (1963).

7) A. Shirota: Nippon Suisan Gakkaishi, 36, 353368 (1970).

8) J. R. Hunter: Fish. Bull., 70, 821-838 (1972).

9) Y. Takemura: Bull. Tokai Reg. Fish. Res. Lab., 15, 29-37 (1957).

10) M. Omori: Int. Rev. Gesamt. Hydrobiol., 63, 266-269 (1978).

11) N. Nakata and C. Imai: Res. Rep. Kanagawa Pref. Fish. Exp. St., 3, 19-28 (1981).

12) A. Kuwabara and S. Suzuki: Nippon Suisan Gakkaishi, 50, 1285-1292 (1984).

13) T. Asami: Cont. Nankai Reg. Fish. Res. Lab., 3, 1-7 (1953).

14) C. Imai: Bull. Japan. Soc. Fish. Oceanogr., 51, 149-152 (1987).

15) A. J. southward and N. Demir: in "Early Life History of Fish" (ed. by J. H. S. Blaxter), Springer Verlag, Berlin, 1974, pp. 53-68.

16) T. B. Bagenal: J. Fish Biol., 3, 207-219 (1971).

17) T. Kato: Bull. Freshw. Fish. Res. Lab., 25(2), 83-115 (1975).

18) T. Kato: Bull. Freshw. Fish. Res. Lab., 28(1), 61-75 (1978).

19) Y. Tsuruta: Bull. Japan. Soc. Fish. Oceanogr., 51, 146-149 (1987).

20) D. Lack: in "Evolution as a Process" (ed. by A. C. Hardy and E. B. Ford) Allen and Unwin, London, 1954, pp. 143-156.

21) Y. Ito: Comparative Ecology, 2nd. ed., Iwanami, Tokyo, 1980, pp. 1-421.

22) D. H. Cushing: Marine Ecology and Fisheries, Cambridge Univ. Press, London, 1975, pp. 1-278.

23) S. Funakoshi: Biological Research of Alternation of Species Composition of Iwasi Sirasu, Fish. Agency, 1984, pp. 129-192.

24) A. Taniguchi: Bull. Japan. Soc. Fish. Oceanogr., 
39, 66-68 (1981).

25) Kanagawa Prefectural Fisheries Experimental Station: Annual Reports for Expectation of Fisheries and Oceanographic Conditions, 19661985.
26) N. Ogawa: Bull. Seikai Reg. Fish. Res. Lab., 48, 1-22 (1976).

27) T. Nakahara and Y. Ogawa: Bull. Japan, Soc. Fish. Oceanogr., 34, 21-31 (1979). 